\title{
Design of static synchronous series compensator based damping controller employing invasive weed optimization algorithm
}

\author{
Ashik Ahmed ${ }^{1 *}$, Rasheduzzaman Al-Amin² and Ruhul Amin ${ }^{3}$
}

\begin{abstract}
This paper proposes designing of Static Synchronous Series Compensator (SSSC) based damping controller to enhance the stability of a Single Machine Infinite Bus (SMIB) system by means of Invasive Weed Optimization (IWO) technique. Conventional PI controller is used as the SSSC damping controller which takes rotor speed deviation as the input. The damping controller parameters are tuned based on time integral of absolute error based cost function using IWO. Performance of IWO based controller is compared to that of Particle Swarm Optimization (PSO) based controller. Time domain based simulation results are presented and performance of the controllers under different loading conditions and fault scenarios is studied in order to illustrate the effectiveness of the IWO based design approach.
\end{abstract}

Keywords: Invasive weed optimization; Static synchronous series compensator; Single machine infinite bus power system; Power oscillation damping (POD); Integral of time absolute error

\section{Introduction}

Power oscillation is a familiar dynamic fact that arises in power system when subjected to disturbance. If adequate damping is not provided, these unwanted oscillations may survive and cause system separation (Kundur 1994). Power system stabilizers (PSS) came into forth with the idea of damping these oscillations by injecting supplementary excitation control signal and increase the stability of the power system. However, PSS were found responsible for causing significant variations in voltage level which may lead to power system instability during the time of three phase faults.

Flexible ac transmission systems (FACTS) utilize power electronic based fast switching devices which can control power flow in the lines and improve stability (Padiyar 2007). FACTS devices are considered as the prominent ones among many effective means to improve operation of power system, increase power transfer capacity etc. Series capacitive compensation method has been employed to remove significant portion of the reactive line impedance and hence improve the amount of transmittable power

\footnotetext{
* Correspondence: ashikhmd@yahoo.com

${ }^{1}$ EEE Department, Islamic University of Technology, Board Bazar, Bangladesh Full list of author information is available at the end of the article
}

under dynamic conditions. Static Synchronous Series Compensator is a voltage source converter based FACTS device which is connected in series with the transmission line (Gyugi et al. 1997).

SSSC injects a controllable and almost sinusoidal voltage which remains in series with the transmission network (Hingorani \& Gyugi 2000). The injected voltage source imposes virtual reactance in the line which in turn controls the power flow of the transmission line. This control of line power flow is independent of the magnitude of the line current (Hingorani \& Gyugi 2000). The ability of SSSC to operate in both inductive and capacitive mode makes it very efficient in controlling the power flow in the system. In either case the injected voltage remains in quadrature with the line current and therefore acts as capacitive or inductive reactance in series with the transmission line. Besides controlling line power flow, SSSC offers good response time with perfectly smooth transition from (+ve) positive to $(-\mathrm{ve})$ negative power through zero voltage injection. Unlike other series compensating devices, SSSC does not run the risk of getting into classical resonance issues at fundamental frequency operation because of the fact that for every practical scenarios line inductance (L) is essentially regulated by injected compensating voltage 


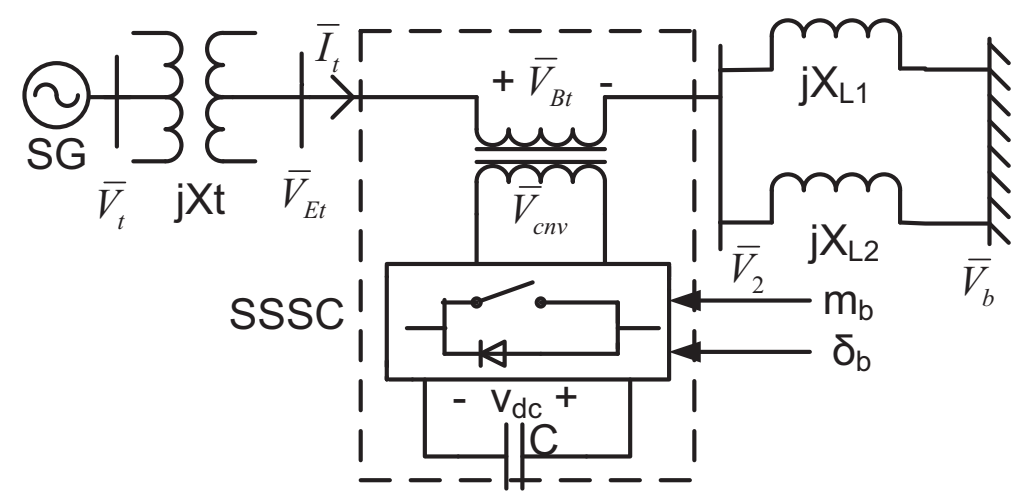

Figure 1 Single machine infinite bus power system with SSSC.

produced (Acha et al. 2004). Aside from controlling the power flow of the line, SSSC can be utilized as a Power Oscillation damping (POD) device through modulation of series reactive power compensation (Zhang et al. 2006). The energy storage ability of SSSC can enhance the effectiveness of POD by absorbing or injecting real power into the transmission line.

The attractive features and effectiveness of SSSC has made its use widespread in very short period. The SSSC based damping controller design has been handled differently in recent literatures. Time optimal control theory has been employed to design a SSSC based damping controller in (Pandey \& Singh 2008). A simplified two area system is considered and the linearized power system model is used. The drawback of this work is that the solution of the Riccati equation is time consuming and large matrix manipulations are required to obtain the desired result. Three different operating modes of SSSC are identified in (David \& Venkataramanan 2007) and the controller design problem is handled by frequency domain based loop shaping technique. The results presented shows that the response time taken by the proposed controllers is quite large. Tuning of the SSSC damping controller is performed by real coded genetic algorithm (RCGA) in (Swain et al. 2011). An integral time absolute error based objective function is selected and deviation in the rotor speed from the synchronous speed is referred as the error. Like genetic algorithm, RCGA, too, has a tendency to get stuck at a local minimum of the solution space. A differential evolution (DE) based approach is proposed in (Swain et al. 2013). Built-in Simulink blocks are used for the analysis which may not allow much freedom for the user to work with. No information is provided regarding the convergence scenario of the proposed algorithm which is one of the major criteria to evaluate an optimization algorithm. Similar drawbacks are observed in (Swain et al. 2012). Adaptive Neuro-fuzzy inference system (ANFIS) is employed to design the damping controller of SSSC in a multi-machine power system network (Murali \& Rajaram 2010). The deviation in line power is taken as the error signal for the controller and the output is the SSSC injected voltage magnitude. Self- tuning PID controller is utilized in (Therattil \& Panda 2011) to damp out electromechanical oscillations. The responses show that it takes around 5 seconds to completely suppress the oscillations. Nonlinear adaptive control technique is proposed for the SSSC damping controller design (Gu et al. 2010). Like any adaptive control algorithm, it takes a healthy computation time to get the required control effort. Design of SSSC damping controller is modeled as a multi-objective optimization problem and

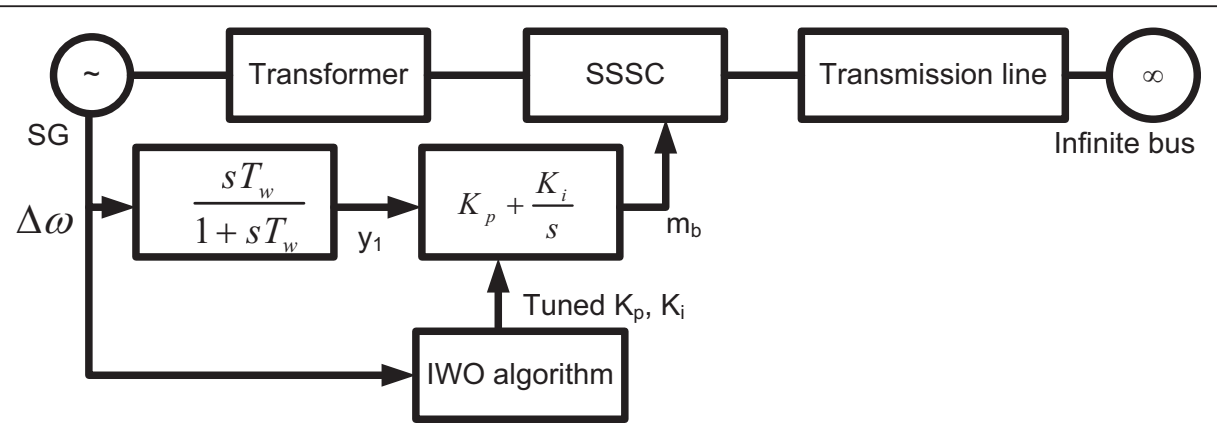

Figure 2 SSSC damping controller connected to the SMIB system. 


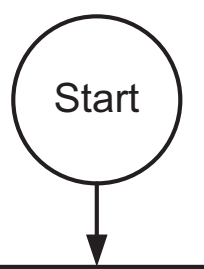

Randomly initialize
population of weeds

and their locations

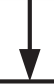

Calculate the fitness

of each weeds

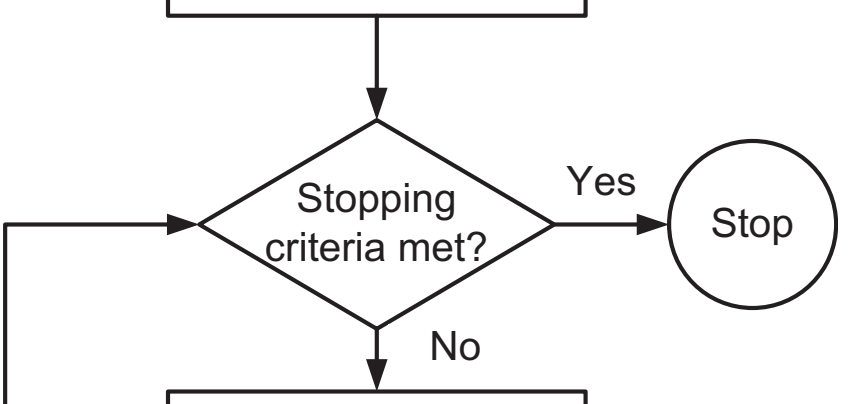

Reproduce seeds depending on their

fitness value
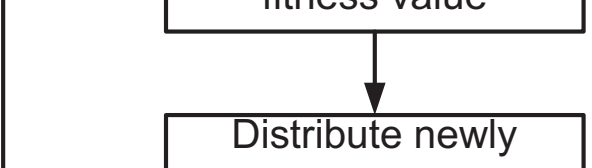
produced seeds within the search space

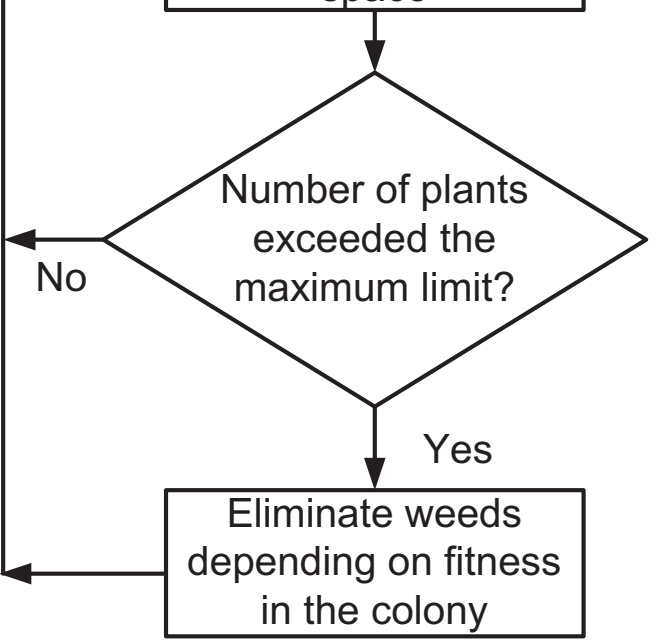

Figure 3 Flowchart of IWO algorithm. 
solved using Particle Swarm Optimization (PSO) algorithm in (Ajami \& Armaghan 2010). Different loading scenarios are considered to show the effectiveness of the proposed method. Nonlinear feedback linearization control technique is employed in (Ghaisari \& Bakhshai 2005) where the study system dynamic model is represented as a multiinput multi-output system. Although the paper describes the need of zero-dynamic study for the stability of overall system, it is not explained for the study system.

Invasive Weed Optimization (IWO) is a recent metaheuristic search algorithm which is inspired from the weed colonizing technique (Mehrabian \& Lucas 2006). IWO was tested for different multi-dimensional benchmark systems and the performance is compared with other efficient search algorithms. Performance of IWO was found superior to Genetic Algorithm, Simulated Annealing, Particle Swarm Optimization, Memetic Algorithm and Shuffled Frog Leaping algorithm. From then on IWO has found numerous applications in diversified field of engineering and science. IWO is efficiently applied for optimizing and tuning of a robust controller (Mehrabian \& Lucas 2006), designing an E-shaped MIMO antenna (Mallahzadeh et al. 2009), optimal positioning of piezoelectric actuators (Mehrabian \& Yousefi-Koma 2007), studying the electricity market dynamics (Ardakani et al. 2008), designing the encoding sequences for DNA computing (Zhang et al. 2009), and developing a recommender system $(\operatorname{Rad} \&$ Lucas 2007).

This paper utilizes the superior performance of IWO to find out the optimal parameter of SSSC damping controller in an SMIB system. A time-domain based objective function is chosen which considers deviation in the rotor speed as error signal and the job of the optimizer is to minimize the error in the quickest possible time. The performance of IWO is then compared to that of PSO based controller.

The paper is organized as follows: Mathematical model discusses the system investigated and SSSC structure, Invasive weed optimization discusses Invasive Weed Optimization Algorithm. The simulation results are presented and discussed in Simulation results. Finally, the conclusions are given in Conclusion.

\section{Mathematical model}

\section{System model and SSSC structure}

Consider a single machine infinite bus system with static synchronous series compensator in series with transmission line as depicted in Figure 1.

The SSSC comprising of a voltage source converter, a series injection transformer and a dc-storage capacitor is indicated in a dotted block. The SSSC injects $\bar{V}_{B t}$ into the transmission line which can be modulated for control of power flow in the line. The control variables are the modulation index $\mathrm{m}_{\mathrm{b}}$ and phase angle $\delta_{\mathrm{b}}$ of the voltage source converter.

The synchronous generator (SG) is represented by the 3rd order non-linear mathematical model with IEEE- ST1 type exciter (Anderson \& Fouad 1977). The SG terminal voltage is represented by $\bar{V}_{t}$. The transformer with reactance $\mathrm{X}_{\mathrm{t}}$ steps up the generator voltage to $\bar{V}_{E t}$. The SSSC series injection transformer boosts up the voltage $\bar{V}_{c n v}$ to $\bar{V}_{B t}$. The relation between the fundamental frequency component of $\bar{V}_{B t}$ and the dc capacitor voltage $\mathrm{V}_{\mathrm{dc}}$ is (Therond 1999):

$$
\bar{V}_{B t}=\frac{m_{b} V_{d c} \angle \delta_{b}}{2}
$$

$\bar{V}_{2}$ and $\bar{V}_{b}$ are the mid-bus and infinite bus voltage, respectively. XL1 and XL2 represent reactance of the parallel transmission lines. The infinite bus voltage is taken as the reference with a constant magnitude. The swing equation of the $\mathrm{SG}$ is given as:

$$
\begin{aligned}
& \dot{\delta}=\omega_{o}(\omega-1) \\
& \dot{\omega}=\frac{\mathrm{P}_{m}-\mathrm{P}_{e}-D(\omega-1)}{M}
\end{aligned}
$$

The q-axis transient voltage dynamics is given as:

$$
\dot{E}_{q}^{\prime}=\frac{E_{f d 0}+\Delta E_{f d}-E_{q}^{\prime}-\left(x_{d}-x_{d}^{\prime}\right) I_{t d}}{T_{d o}^{\prime}}
$$

The exciter dynamics is represented as:

$$
\dot{\Delta E_{f d}}=\frac{K_{A}\left(\mathrm{~V}_{R E F}-\mathrm{V}_{t}\right)}{T_{A}}-\frac{\Delta E_{f d}}{T_{A}}
$$

Dynamics of SSSC dc link voltage is:

$$
\dot{V}_{d c}=\frac{3 m_{b} I_{t d} \cos \delta_{b}}{4 C_{d c}}+\frac{3 m_{b} I_{t q} \sin \delta_{b}}{4 C_{d c}}
$$

The algebraic quantities appearing in equations (2) (6) are given as follows:

$$
\begin{aligned}
& P_{e}=V_{t d} I_{t d}+V_{t q} I_{t q} \\
& V_{t q}=E_{q}^{\prime}-x_{d}^{\prime} I_{t d} \\
& V_{t d}=x_{q} I_{t q}
\end{aligned}
$$

Applying KVL at different nodes of Figure 1:

Table 1 Various loading conditions

\begin{tabular}{llll}
\hline Loading condition & $\mathbf{P}_{\mathbf{e}}(\mathbf{p} . \mathbf{u})$ & $\mathbf{V}_{\mathbf{t}}$ (p.u) & $\mathbf{Q}_{\mathbf{e}}(\mathbf{p} . \mathbf{u})$ \\
\hline Light & 0.8 & 1.0 & 0.0808 \\
Nominal & 1.0 & 1.0 & 0.127 \\
Heavy & 1.2 & 1.1 & 0.6068 \\
\hline
\end{tabular}


Table 2 IWO and PSO parameters

\begin{tabular}{lllll}
\hline IWO & & & PSO & \\
\cline { 1 - 2 } \cline { 5 - 6 } Parameter & Value & & Parameter & Value \\
\hline Population & 30 & & Population & 30 \\
$\mathrm{~m}$ & 500 & & Number of generation & 500 \\
$\mathrm{~S}_{\mathrm{i}}$ & 3 & & weight & 0.9 \\
$\mathrm{~S}_{\mathrm{f}}$ & 1 & & alpha & 0.99 \\
& 0.0001 & &
\end{tabular}

$$
\begin{aligned}
& \bar{V}_{t}=j X_{t} \bar{I}_{t}+\bar{V}_{E t} \\
& \bar{V}_{E t}=\bar{V}_{B t}+j X_{L} \bar{I}_{t}+\bar{V}_{b}
\end{aligned}
$$

Combining (8) and (9) the following is obtained:

$$
V_{t d}+j V_{t q}=x_{q} I_{t q}+j\left(E_{q}^{\prime}-x_{d}^{\prime} I_{t d}\right)
$$

Equation (11) can be re-written in terms of $\mathrm{d}$ and $\mathrm{q}$ components:

$$
\begin{aligned}
& V_{t d}+j V_{t q}=x_{q} I_{t q}+j\left(E_{q}^{\prime}-x_{d}^{\prime} I_{t d}\right) \\
& =j \mathrm{X}_{t}\left(I_{t d}+j I_{t q}\right)+V_{B t d}+j V_{B t q}+V_{b d}+j V_{b q}
\end{aligned}
$$

The $\mathrm{d}$ and $\mathrm{q}$ components of the booster transformer voltage $\mathrm{V}_{\mathrm{Btd}}$ and $\mathrm{V}_{\mathrm{Btq}}$ can be expressed as:

$$
\begin{aligned}
V_{B t d} & =\frac{m_{b} V_{d c} \cos \delta_{b}}{2} \\
V_{B t q} & =\frac{m_{b} V_{d c} \sin \delta_{b}}{2}
\end{aligned}
$$

The $\mathrm{d}$ and $\mathrm{q}$ components of the infinite bus voltage can be written as:

$$
V_{b d}=V_{b} \sin \delta
$$

$$
V_{b q}=V_{b} \cos \delta
$$

Equating the R.H.S. of equations (12) and (13) and solving for $I_{t d}$ and $I_{t q}$ using the expressions from (14)-(17):

$$
\begin{aligned}
I_{t d} & =\frac{\left(\mathrm{E}_{q}^{\prime}-\frac{m_{b} V_{d c} \sin \delta_{b}}{2}-V_{b} \cos \delta\right)}{X_{4}} \\
I_{t q} & =\frac{\left(\frac{m_{b} V_{d c} \cos \delta_{b}}{2}-V_{b} \sin \delta\right)}{X_{3}}
\end{aligned}
$$

where,

$$
\begin{aligned}
& X_{3}=x_{q}+X_{t}+X_{L} \\
& X_{4}=x_{d}^{\prime}+X_{t}+X_{L} \\
& X_{L}=X_{L 1} \| X_{L 2}
\end{aligned}
$$

\section{SSSC damping control}

The damping controller configuration of the SSSC is depicted in Figure 2. Among the two control signals available, the modulation index $\mathrm{m}_{\mathrm{b}}$ has been used in this paper as it shows greater controllability over $\delta_{\mathrm{b}}$ (Therattil \& Panda 2011).

The rotor speed deviation $\Delta \omega$ is achieved by introducing different dynamic scenarios for different loading conditions. The system is initialized each time there is any change in operating condition. The rotor speed deviation is taken as the input to the PI controller through a wash-out block. The same speed deviation signal is passed to the IWO optimizer which calculates an objective function and tries to obtain an optimal solution to the problem at hand by minimizing the deviation in the speed signal. The IWO optimizer then sends the optimized parameter set (in this case $\mathrm{K}_{\mathrm{p}}$ and $\mathrm{K}_{\mathrm{i}}$ ) to the controller block and the controller output gives the desired magnitude of modulation index $\left(m_{b}\right)$ in order to improve the system damping. The optimizer is applied for a certain fault case and loading condition.

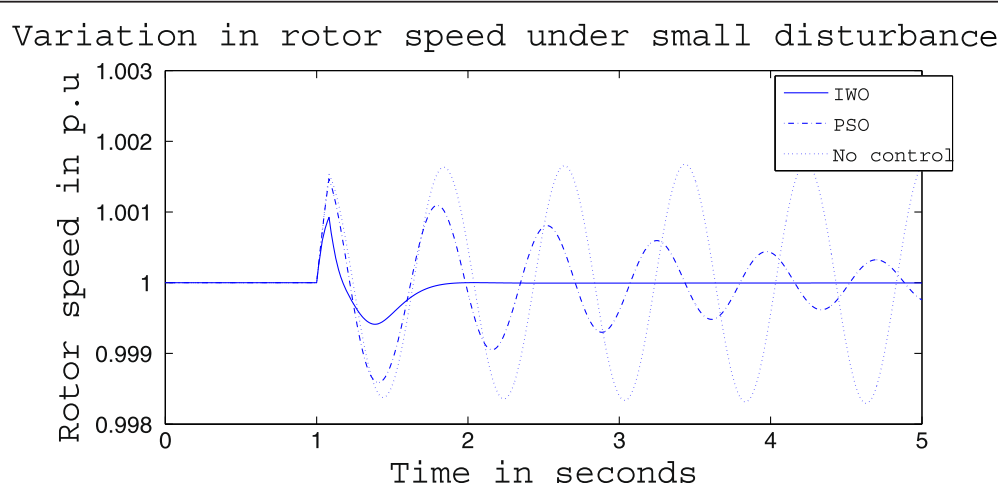

Figure 4 Rotor speed response for case (i) under light load condition. 


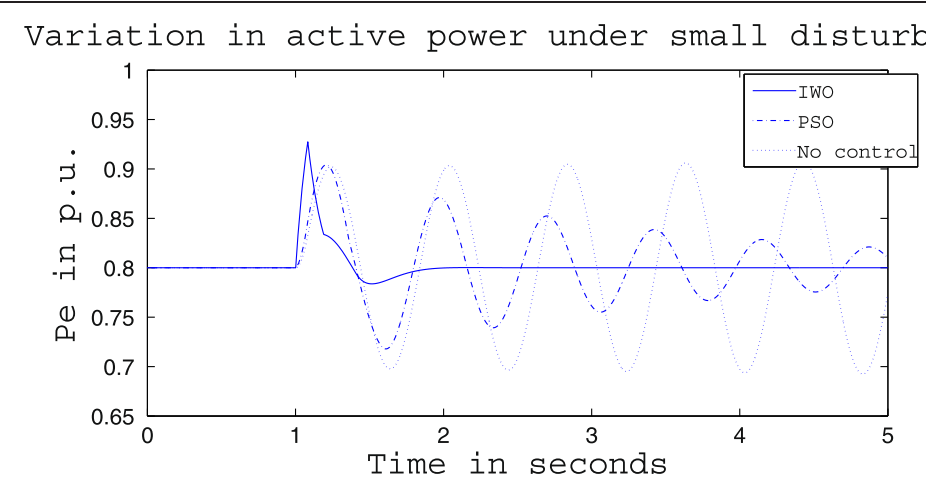

Figure 5 Active power response for case (i) under light load condition.

With the introduction of the PI controller along with a wash-out block, the new dynamic equations are:

$$
\begin{aligned}
& \dot{y}_{1}=\Delta \dot{\omega}-\frac{y_{1}}{T_{w}} \\
& \dot{m}_{b}=\Delta \dot{\omega} * K_{p}-\frac{y_{1}}{T_{w}} * K_{p}+y_{1} * K_{i}
\end{aligned}
$$

\section{Objective function}

The design of the PI based SSSC damping controller is formulated as a single objective constrained optimization problem and solved by IWO technique. The objective function considered in this paper is:

$$
J=\int_{0}^{t s i m}|\Delta \omega| d t
$$

where, tsim is the total simulation time. For a certain parameter set, the objective here is to minimize the J value subject to the following constraints:

$$
\begin{aligned}
K_{i \min } & <K_{i}<K_{i \max } \\
K_{p \min } & <K_{p}<K_{p \max }
\end{aligned}
$$

\section{Invasive weed optimization}

Invasive Weed Optimization is a bio-inspired numerical stochastic optimization algorithm that simply simulates natural behavior of weeds in colonizing and finding suitable place for growth and reproduction. Some of the distinctive properties of IWO in comparison with other evolutionary algorithms are the way of reproduction, spatial dispersal, and competitive exclusion (Mehrabian \& Lucas 2006).

\section{The IWO process is summarized as follows: Initialize a random population}

To start with, a random population set is defined over the allocated search space. The allocated search space is generally confined to the constrained boundaries.

\section{Reproduction}

Each randomly produced seeds are tested on the objective function to find out their individual fitness to achieve a certain target. These seeds are now allowed to reproduce depending on their own fitness in a linear fashion, i.e., none of the seeds are excluded from the regeneration phase. Each seed has a chance to reproduce and the reproduction rate varies from the maximum to the minimum for the best to the worst fit seed, respectively.

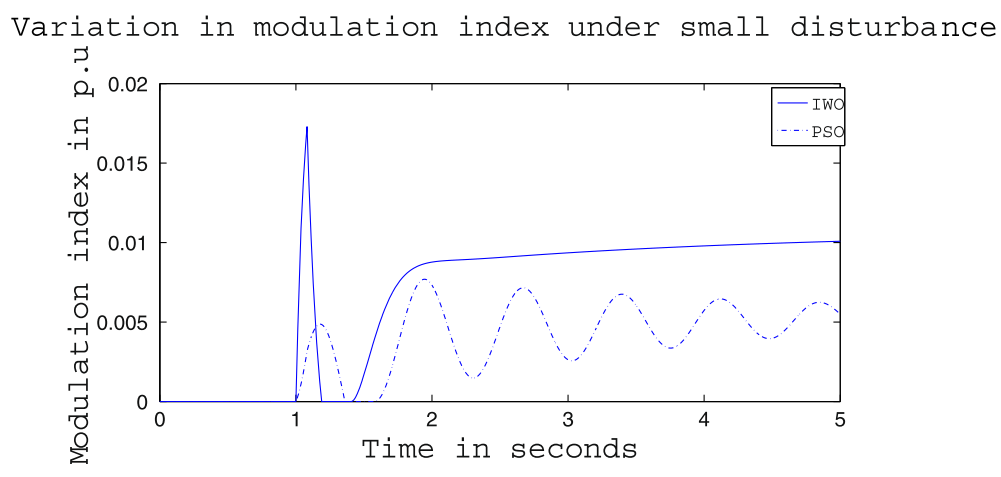

Figure 6 Variation of control signal $m_{b}$ for case (i) under light load condition. 


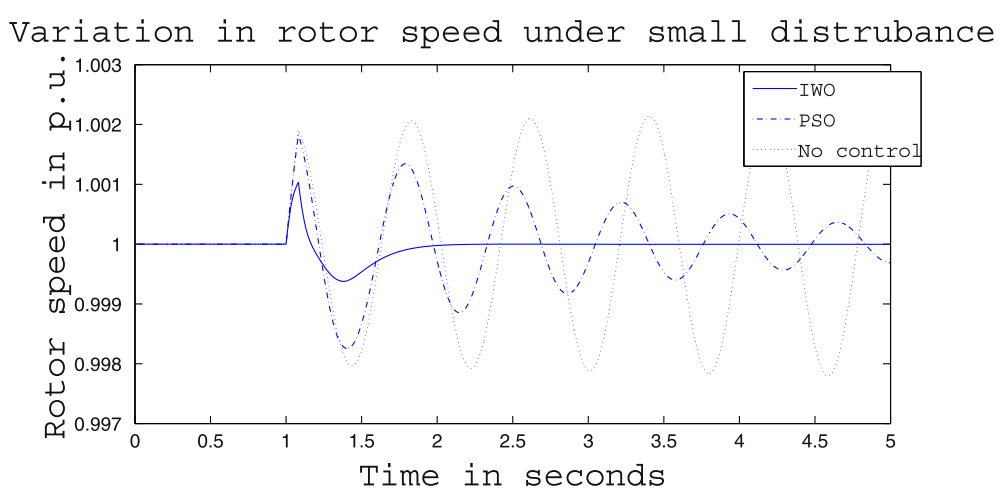

Figure 7 Rotor speed response for case (i) under nominal load condition.

\section{Spatial dispersal}

The reproduced seeds are distributed randomly in such a way that they stay close to the parent plant. This can be achieved by randomly distributing the seeds over the search space with mean equal to zero and variable variance. The standard deviation (SD), is given as;

$$
S_{i t}=\left[\left(i t_{\max }-i t\right) / i t_{\max }\right]^{m} \times\left(S_{i}-S_{f}\right)+S_{f}
$$

where, $\mathrm{it}_{\max }$ is the maximum number of iterations, $\mathrm{S}_{\mathrm{it}}$ is the $\mathrm{SD}$ at the present time step, $\mathrm{m}$ is the nonlinear modulation index, $\mathrm{S}_{\mathrm{i}}$ is the initial $\mathrm{SD}$ and $\mathrm{S}_{\mathrm{f}}$ is the final $\mathrm{SD}$. The produced seeds are then evaluated and allowed to go forward for further production if they provide better solutions than the parent weeds with lower fitness in a colony.

\section{Competitive exclusion}

The dispersed plants should go under competition so that only the best fit plants are kept for further generation. So, after some iteration, whenever the number of plants in a colony reaches the maximum, some of the unfit or less fit plants should be replaced by better fit plants. For this purpose, the parents and the offspring are ranked together and according to the fitness value some of the unfit candidates are excluded from the colony and thus keeping the final set of population equal to the maximum number of plants.

The algorithm stops until the maximum number of iteration ( $\left(\mathrm{it}_{\max }\right)$ is reached or some predefined stopping criterion is fulfilled. In this work, the stopping criteria is set in such a way that if the fitness value does not change for the last 50 iterations, the algorithm would consider that it has obtained an optimal solution. The flowchart of the IWO algorithm is provided in Figure 3.

\section{Simulation results}

The expectation from IWO tuned SSSC damping controller is to provide faster solution to power oscillation damping, quick settling time for the states and the overshoot/undershoot within acceptable limit. This will require some control effort. Again, as there is a hardware limit of designed controller system, for the case of SSSC, the control input parameter $\mathrm{m}_{\mathrm{b}}$ should be within its limit. In this work, the boundaries for the modulation index are set between $m_{b \min }$ and $m_{b \max }$. The values of $m_{b \min }$ and $\mathrm{m}_{\mathrm{bmax}}$ are given in the Appendix.

For any power system, changes in operating conditions of system are common phenomenon. For a good design of

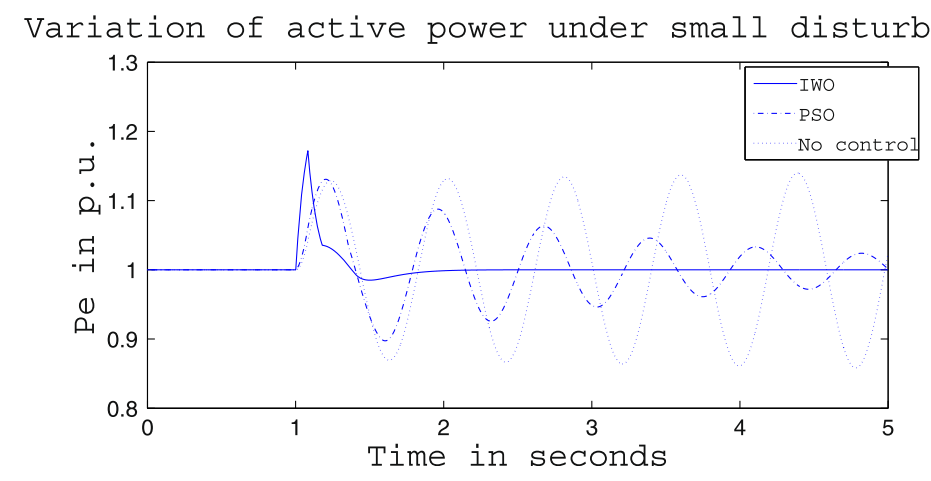

Figure 8 Active power response for case (i) under nominal load condition. 


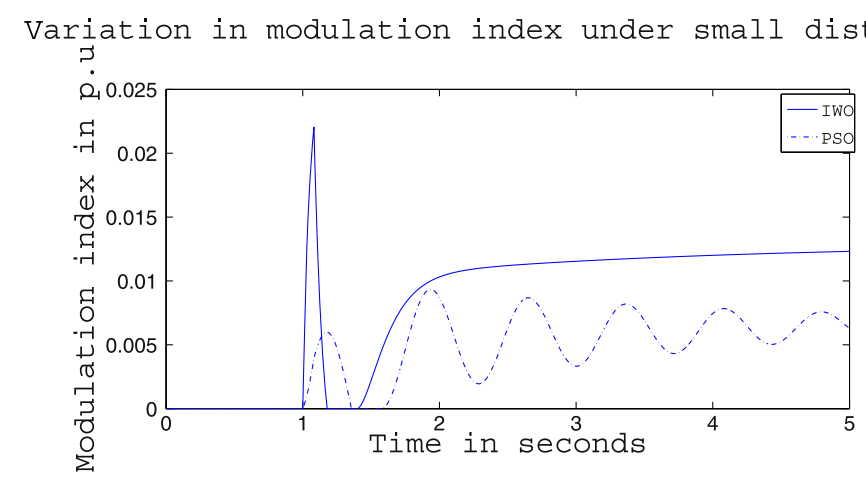

Figure 9 Variation of control signal $m_{b}$ for case (i) under nominal load condition.

damping controller, besides the maximum effectiveness of the controller, the robustness of damping controller to the variations of power system operating conditions is an equally important factor to be taken under consideration. Hence it is desirable for SSSC optimal POD controller to be able to tolerate changes in operating point and the performance should be satisfactory over a range of change of operating conditions. Therefore, it is particularly important to study the effect of load variations on the performance of designed controller. Keeping these in mind, to exhibit the effectiveness of designed POD controller, simulation studies has been carried out for three different operating conditions of the system which are listed in Table 1.

The effectiveness of the optimization algorithm can be interpreted as i) the number of iterations taken by the optimizer to reach at the optimal solution, ii) the level of objective achieved in the form of minimization/ maximization and iii) ability to search for an optimal result within the given constraints. The constraints are interpreted as the boundary values of the PI controller gains and the values are provided in the Appendix. In view of the above, the performance of IWO is compared with that of the Particle Swarm optimization (PSO) for the designing of the controller. Detail discussion on PSO can be found in (Kennedy \& Eberhart 1995).
Numerical values of relevant parameters of the test system are provided in the Appendix. Parameters used for IWO and PSO optimizers are listed in Table 2.

Different simulation cases considered in this work are:

i) A mechanical torque pulse having a magnitude of 0.2 p.u. is applied at $1.0 \mathrm{sec}$ and removed at $1.083 \mathrm{sec}$.

ii) A three phase short circuit fault is applied at the middle of one of the transmission line at $1.0 \mathrm{sec}$ and the fault is cleared at $1.083 \mathrm{sec}$. So, the post fault and the pre fault transmission line reactance remain same.

iii) A three phase short circuit fault is applied at the middle of one of the transmission line at $1.0 \mathrm{sec}$ and the faulted line is removed at $1.083 \mathrm{sec}$. So, the transmission line reactance gets doubled in the post fault period.

All of the above cases are simulated for the three different operating conditions provided in Table 1.

\section{Results and discussion}

Figures 4, 5 and 6 presents the results of case (i) for light load conditions. It is seen that under no control the system experiences oscillatory instability as the rotor angle and active power oscillations are increasing with time.

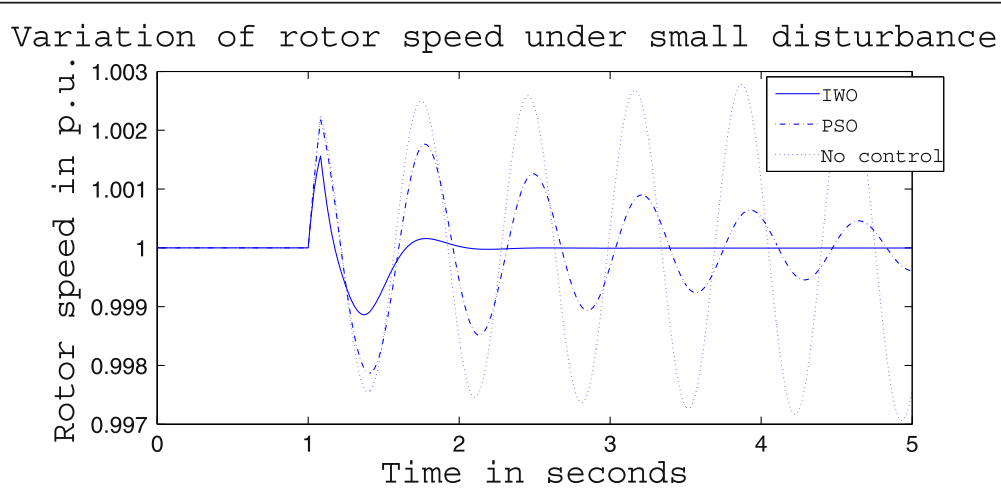

Figure 10 Rotor speed response for case (i) under heavy load condition. 


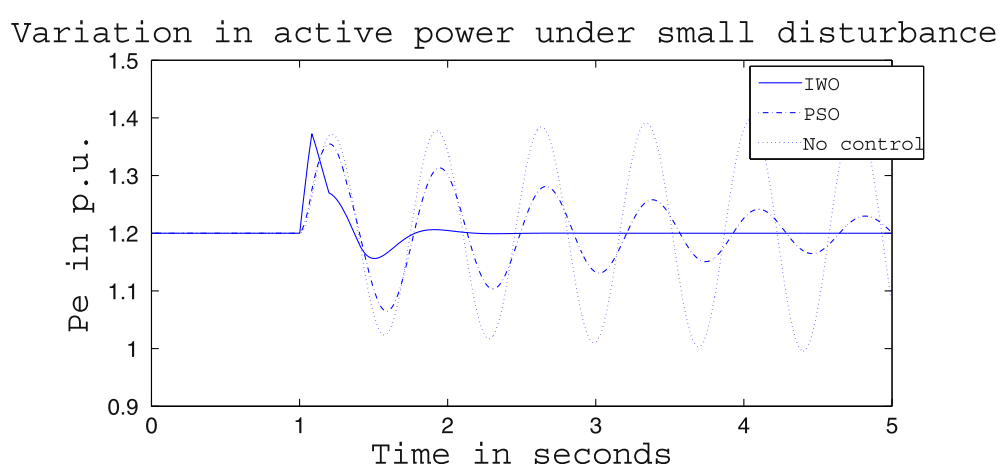

Figure 11 Active power response for case (i) under heavy load condition.

The introduction of optimized control action stabilizes the system for both PSO and IWO algorithms. But the damping action achieved is lot better for IWO than that of PSO. PSO optimized control action dampens the oscillation at a slow rate and even after the $5 \mathrm{sec}$ simulation it requires some more time to reach to a steady value. On the other hand the IWO optimized control action can damp out the system oscillation within $1 \mathrm{sec}$ of the introduction of the dynamics. Figure 6 shows that the control effort required by both algorithms are within the limit but the one with IWO settles to a steady value of 0.01 p.u. whereas the PSO control action keeps oscillating around 0.005 p.u.

Figures 7, 8 and 9 presents the results of case (i) under nominal load condition. With increase in loading level the first swing of the rotor speed goes a little higher but the controller successfully damps out the subsequent oscillations. Here, too, the performance of the IWO optimizer is found superior than the PSO optimizer. Figure 9 ensures the fact that a little more control effort is required for the nominal load condition compared to the light load condition as the IWO optimized control signal settles at around 0.0125 p.u.

Figures 10, 11 and 12 presents the results of case (i) under heavy load condition. Further increase in the first swing of rotor speed is noticed and the superiority of the
IWO optimizer compared to that of PSO is again justified. The control effort requirement in Figure 12 changes ever so slightly compared to the nominal loading case in Figure 9.

The supremacy of IWO optimizer over PSO optimizer is again tested in terms of their performance for converging to a minimum value of the fitness function and the results are provided in Figures 13, 14. Figure 13 shows that the minimization achieved by PSO is in the range of $10^{-5}$ and except in the heavy loading condition the number of iterations taken for convergence is larger than 10 . In comparison, from Figure 14 it is seen that in all cases the algorithm converges within 10 iterations and the minimization achieved is in the order of $10^{-8}$.

Simulation results for case (ii) are presented in Figures 15, $16,17,18,19,20,21,22$ and 23. From Figure 15 it is observed that under this case the rotor speed deviation from the synchronous speed continues for a little longer duration compared to case (i) but the IWO optimizer eventually dampens out the oscillation within 2.0 seconds of the arrival of the fault. The PSO optimizer takes much longer time to reduce the oscillation. Similar observation is found in Figure 16 for active power dynamics. Variation in the control signal $\mathrm{m}_{\mathrm{b}}$ is presented in Figure 17 and it is clear that the IWO optimizer settles to a steady control signal much earlier than the PSO optimizer. Change in

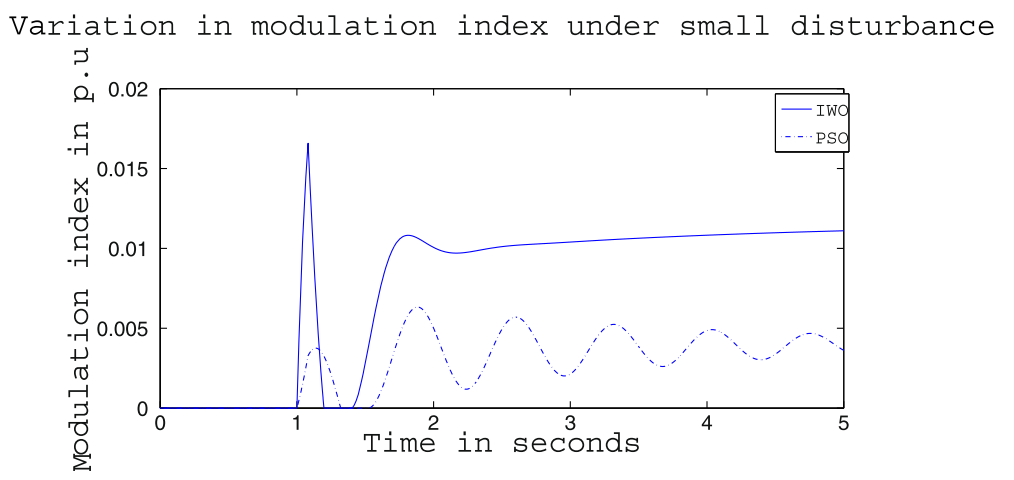

Figure 12 Variation of control signal $m_{b}$ for case (i) under heavy load condition. 


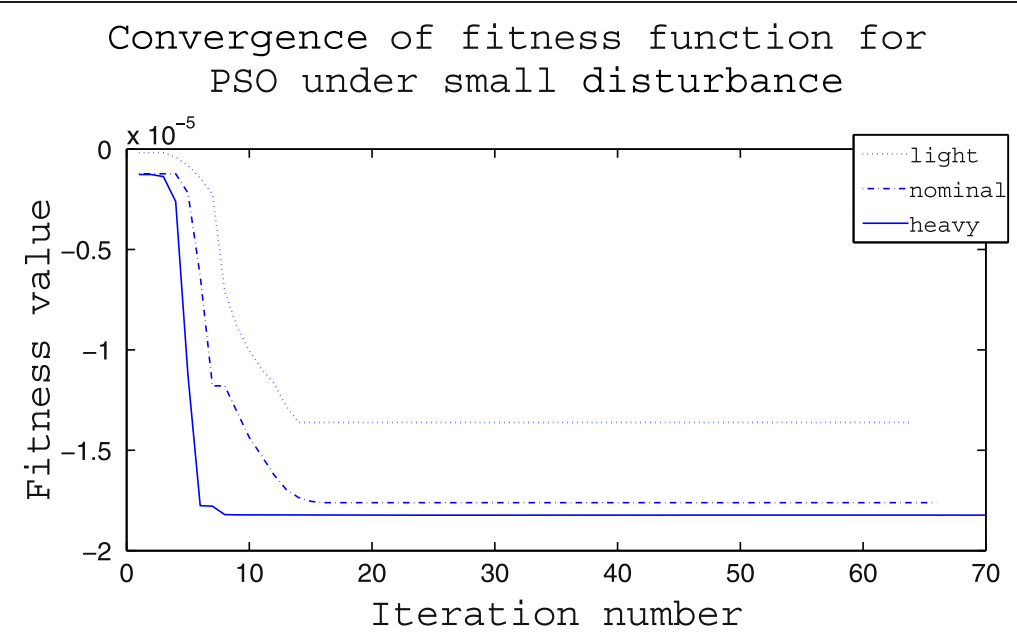

Figure 13 Convergence of PSO optimizer for different loading in case (i).

the operating condition from light to nominal or heavy does not change the outcome of the analysis as found from Figures 18, 19, 20, 21, 22 and 23. Even the change in fault scenario yields the same conclusion regarding the performance of IWO and PSO optimizer which can be observed from Figures 24, 25, 26, 27, 28, 29, 30, 31 and 32 for case (iii).

The plots of the control signal $\left(\mathrm{m}_{\mathrm{b}}\right)$ reveals the fact that in all cases both IWO and PSO can keep the value of the control signal within its maximum and minimum limits. The results of the optimized $K_{p}$ and $K_{i}$ parameters for IWO and PSO are presented in Table 3.

The incidents where the optimizer hits the limit are shown in bolded form. It is found that the PSO optimizer reaches the lower limit of $K_{p}$ in each case and the higher limit of $K_{\mathrm{i}}$ for the first two scenarios. On the other hand, the IWO optimizer hits the upper limit of $K_{\mathrm{i}}$ only in one scenario. This gives an indication of the better performance of IWO in finding an optimal solution within a confined search space.

\section{Conclusion}

Power system stability enhancement using SSSC based damping controller is studied in this paper. A PI controller based design is considered where the optimal parameters of the controller are found by minimizing a time integral of absolute error based objective function. Different fault scenarios and loading conditions are studied for an SMIB system and IWO technique is employed to search for the optimal controller parameters. The performance of IWO optimizer is compared to that of PSO optimizer in a constrained search space. The simulation results show the superiority of IWO over PSO in tuning SSSC controller for the damping of power oscillations of a single machine power system.

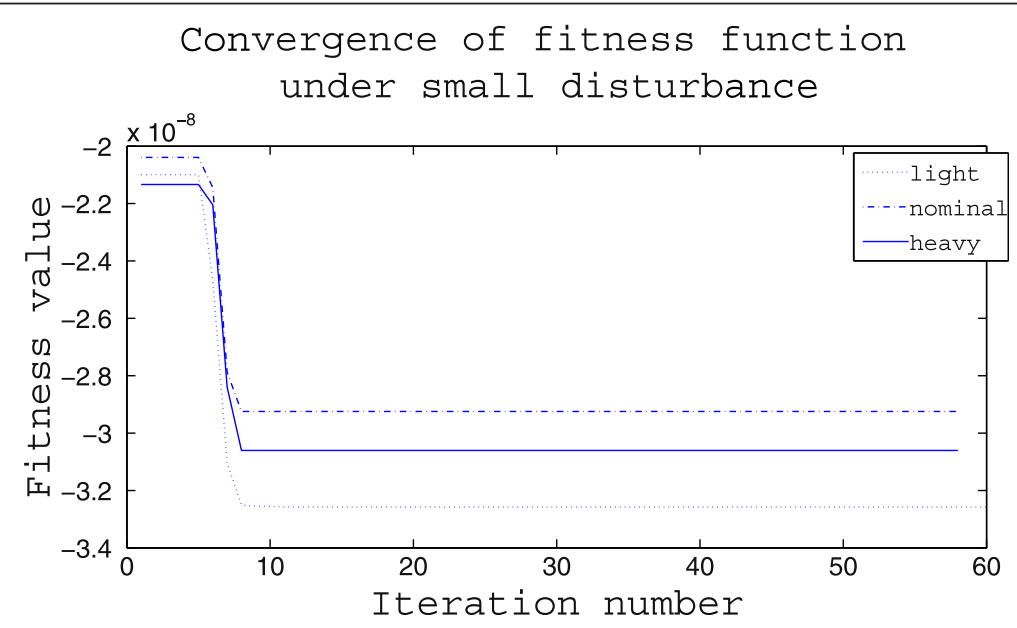

Figure 14 Convergence of IWO optimizer for different loading in case (i). 


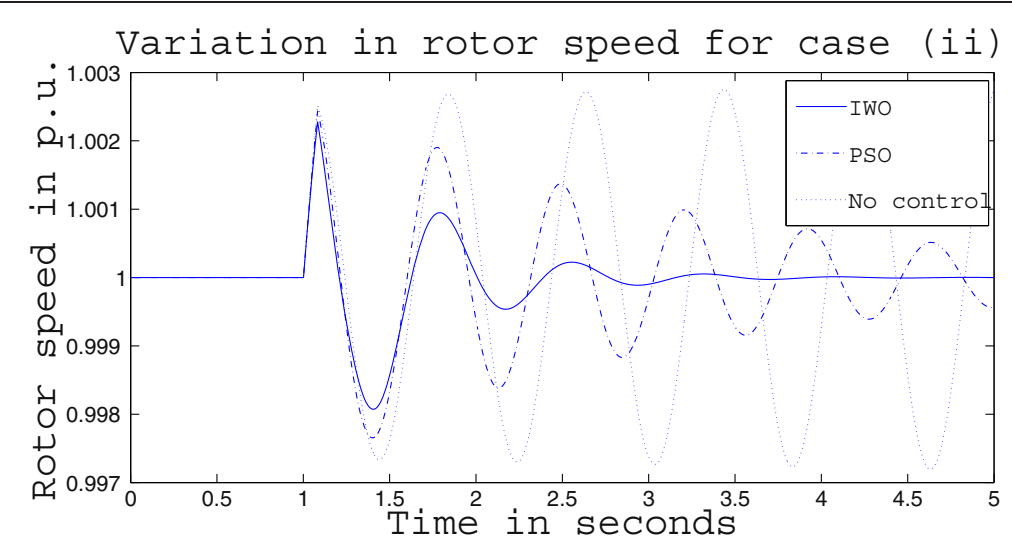

Figure 15 Rotor speed response for case (ii) under light load condition.

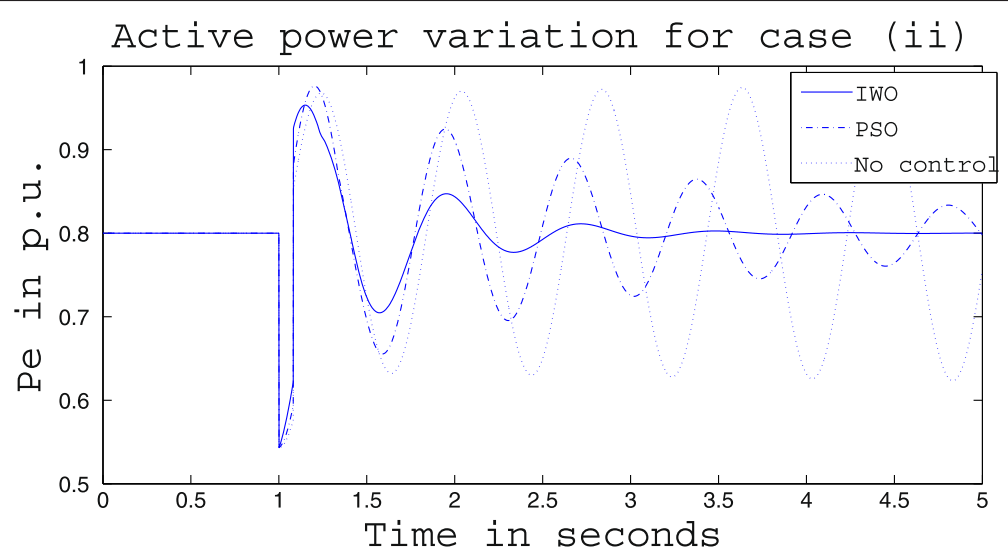

Figure 16 Active power response for case (ii) under light load condition.

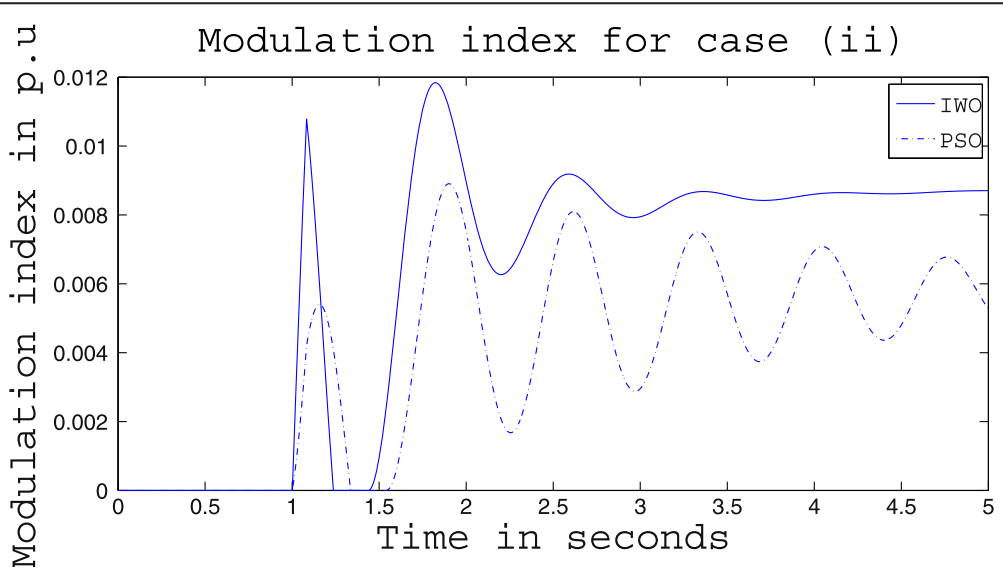

Figure 17 Variation of control signal $m_{b}$ for case (ii) under light load condition. 


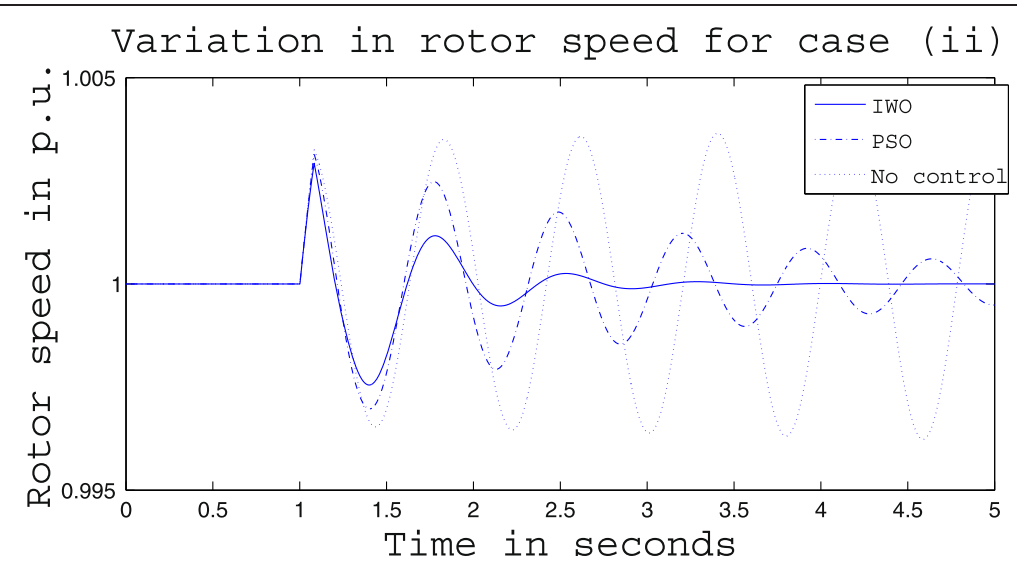

Figure 18 Rotor speed response for case (ii) under nominal load condition.

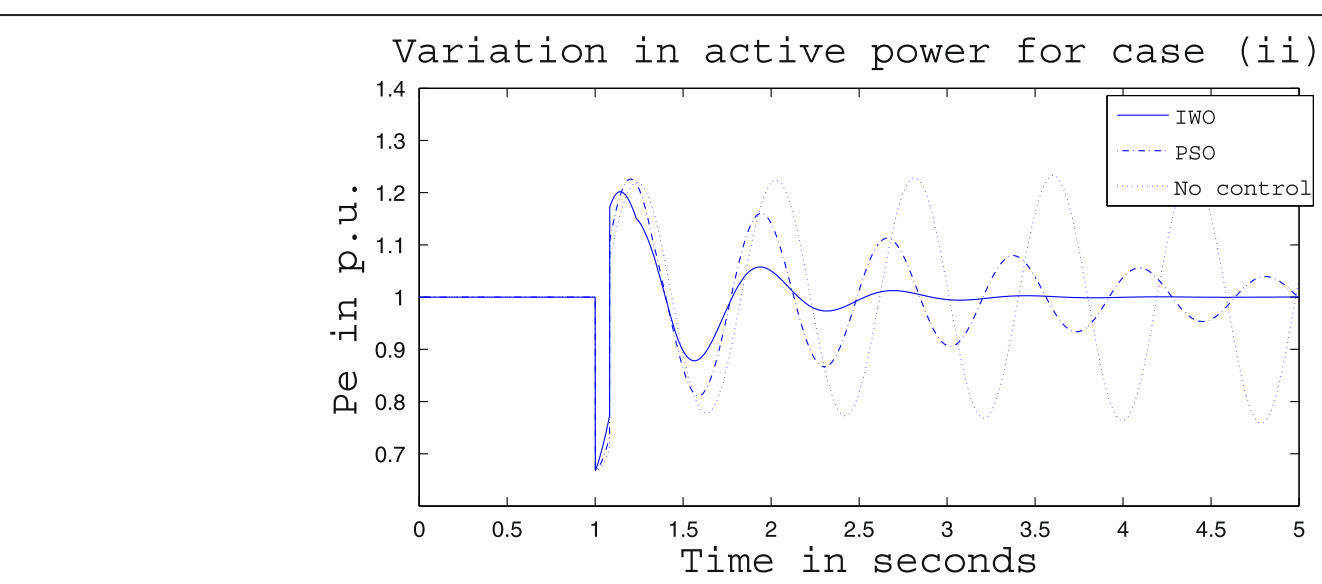

Figure 19 Active power response for case (ii) under nominal load condition.

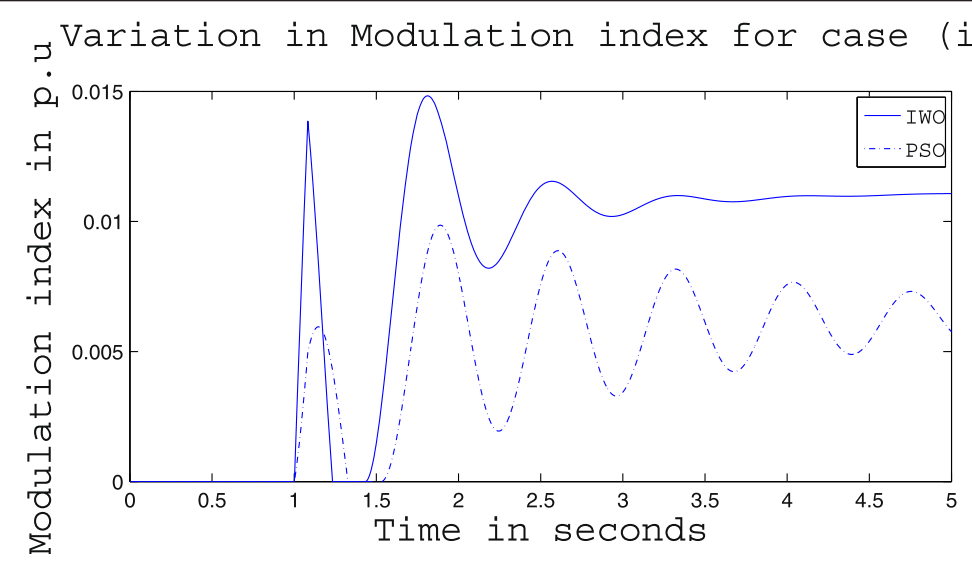

Figure $\mathbf{2 0}$ Variation of control signal $\mathrm{m}_{\mathrm{b}}$ for case (ii) under nominal load condition. 


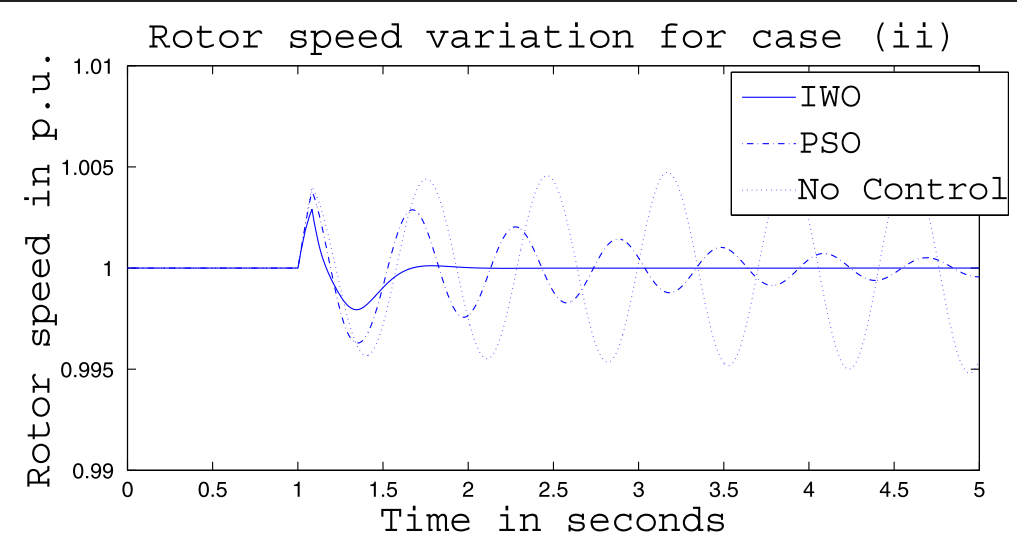

Figure 21 Rotor speed response for case (ii) under heavy load condition.

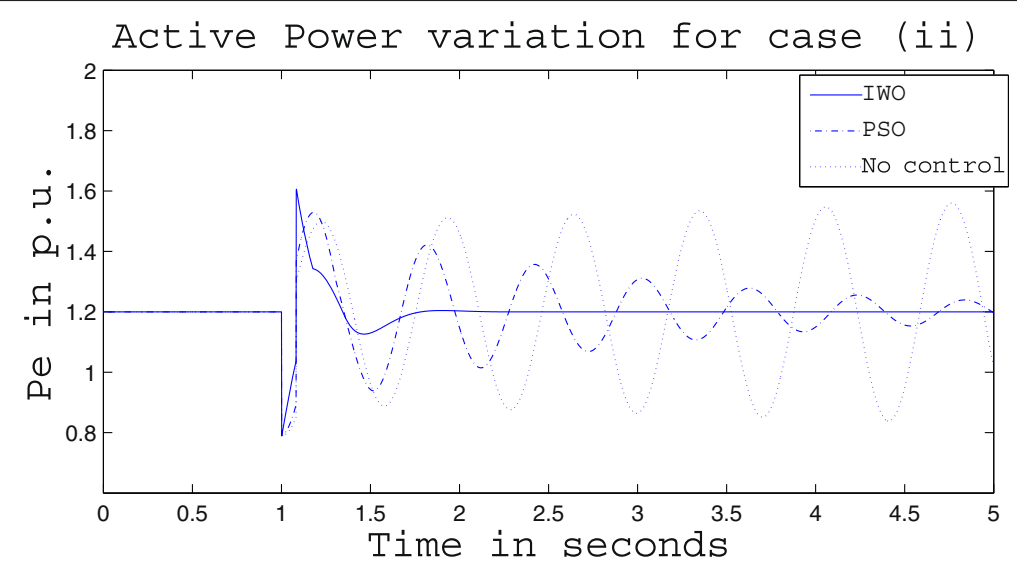

Figure 22 Active power response for case (ii) under heavy load condition.

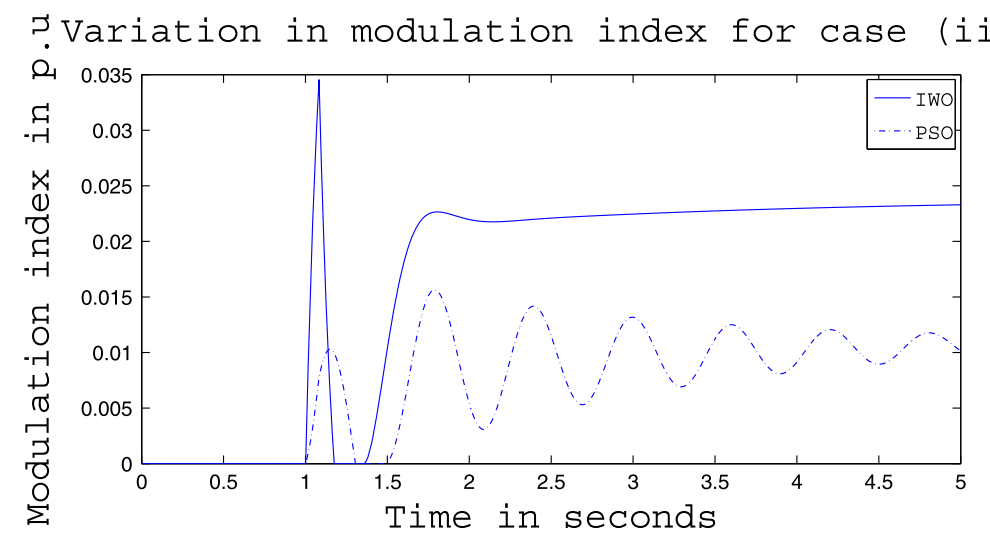

Figure 23 Variation of control signal $m_{b}$ for case (ii) under heavy load condition. 


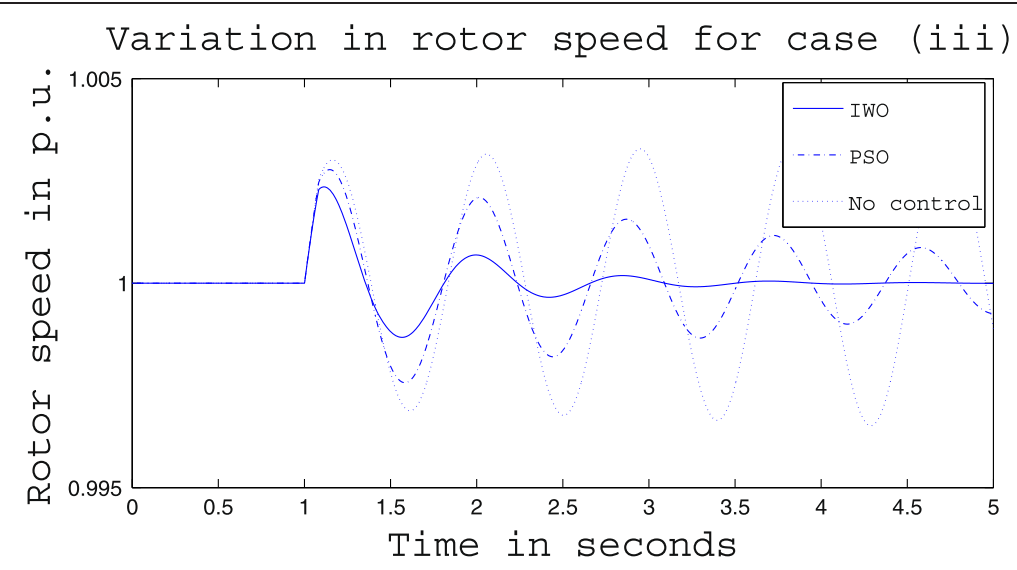

Figure 24 Rotor speed response for case (iii) under light load condition.

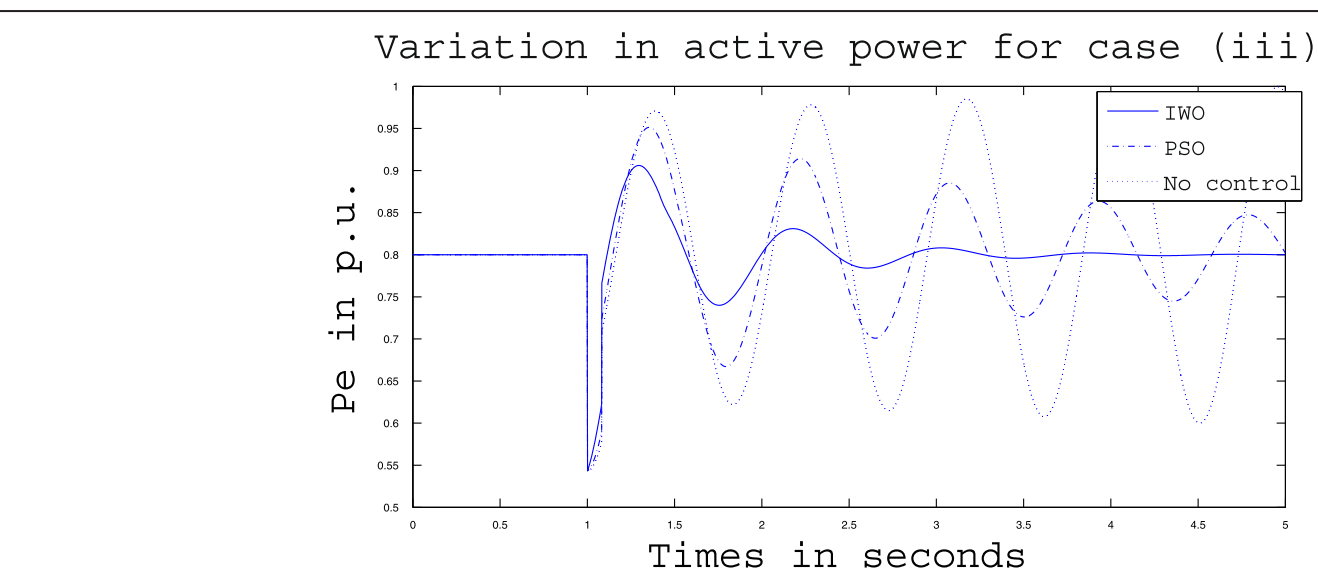

Figure 25 Active power response for case (iii) under light load condition.

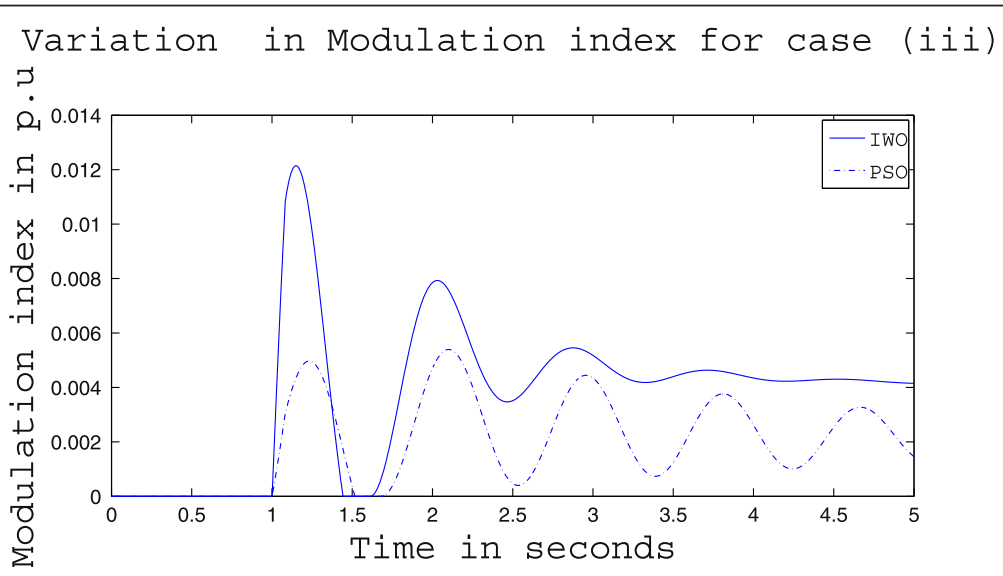

Figure 26 Variation of control signal $m_{b}$ for case (iii) under light load condition. 


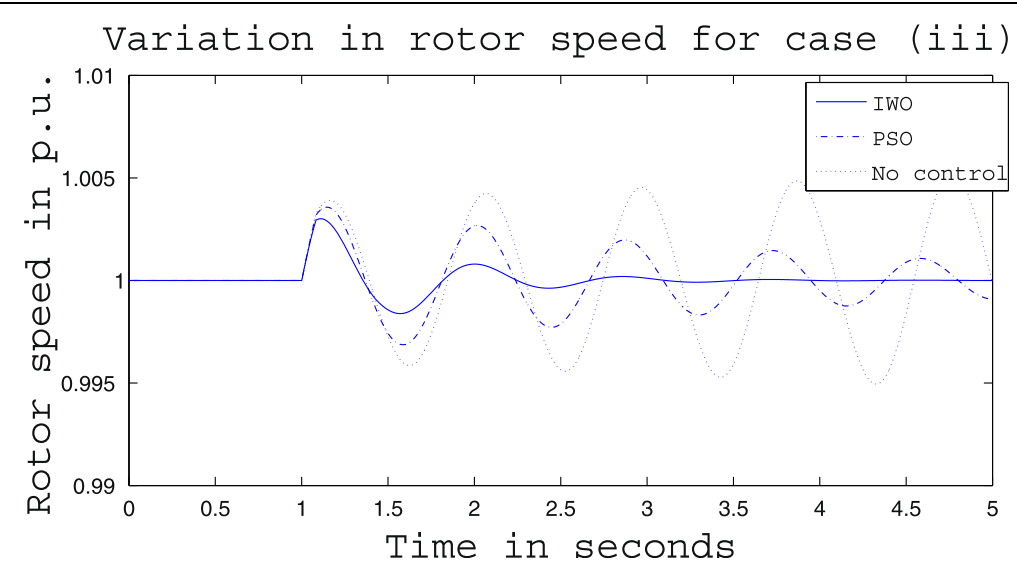

Figure 27 Rotor speed response for case (iii) under nominal load condition.

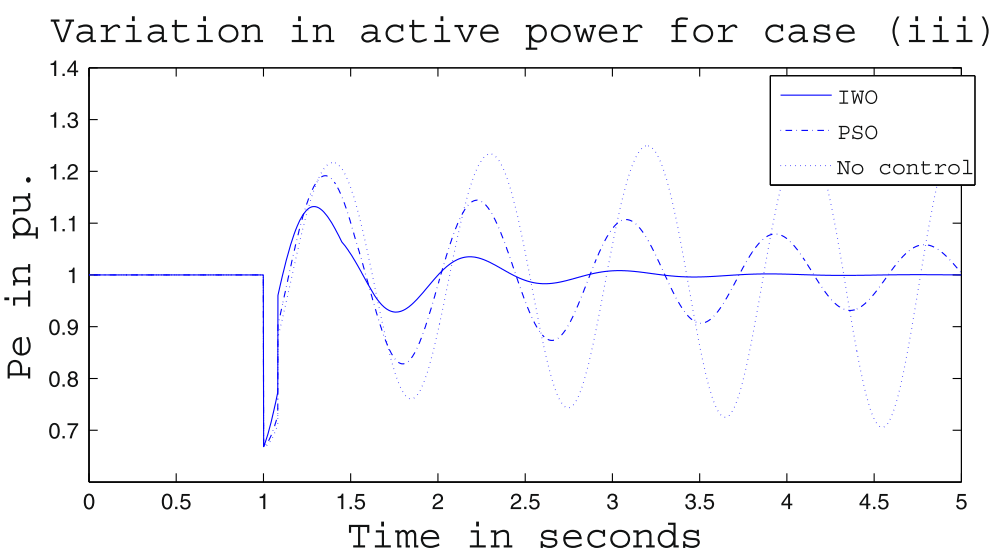

Figure 28 Active power response for case (iii) under nominal load condition.

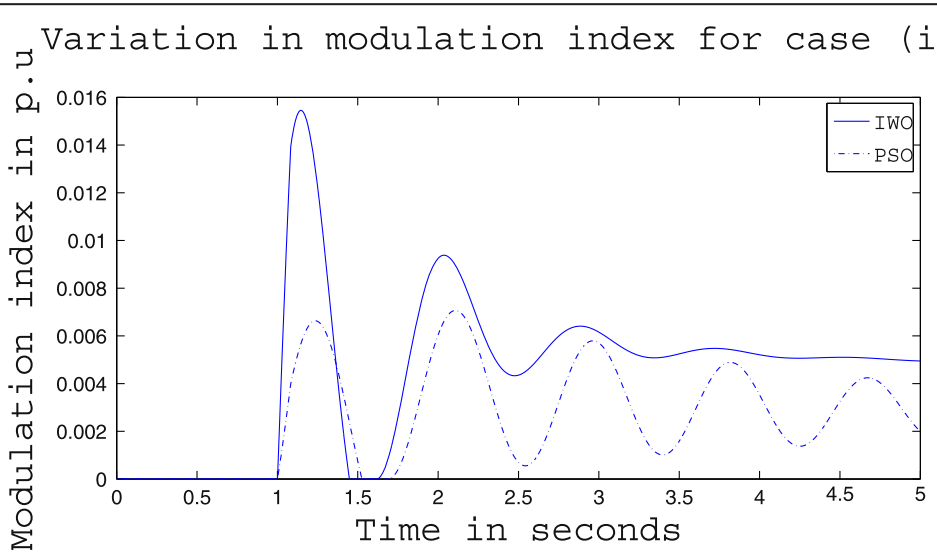

Figure 29 Variation of control signal $\mathrm{m}_{\mathrm{b}}$ for case (iii) under nominal load condition. 


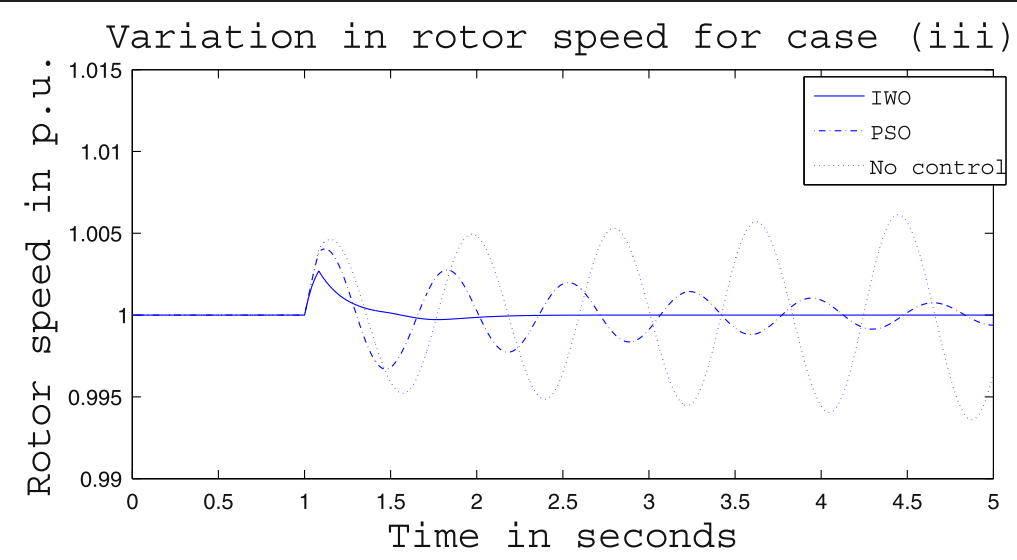

Figure 30 Rotor speed response for case (iii) under heavy load condition.

Variation in active power for case (iii)

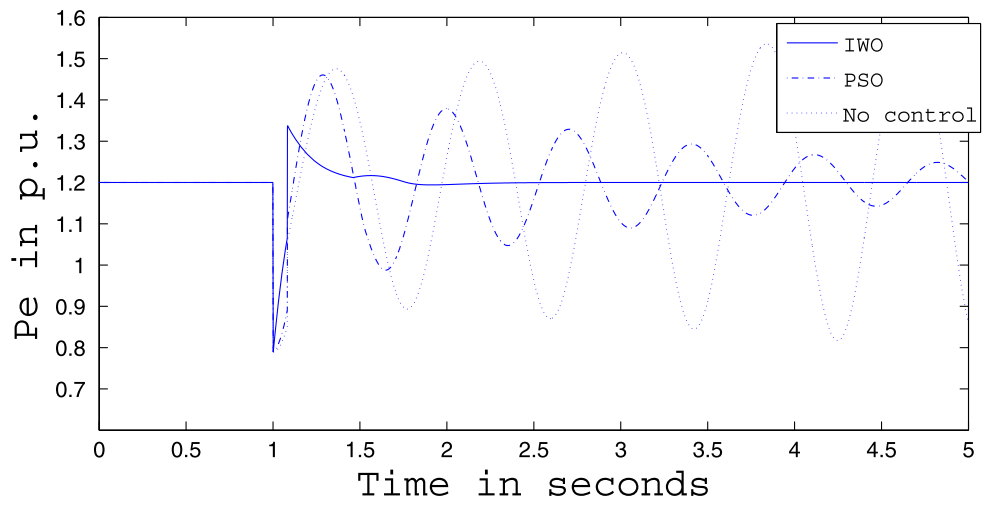

Figure 31 Active power response for case (iii) under heavy load condition.

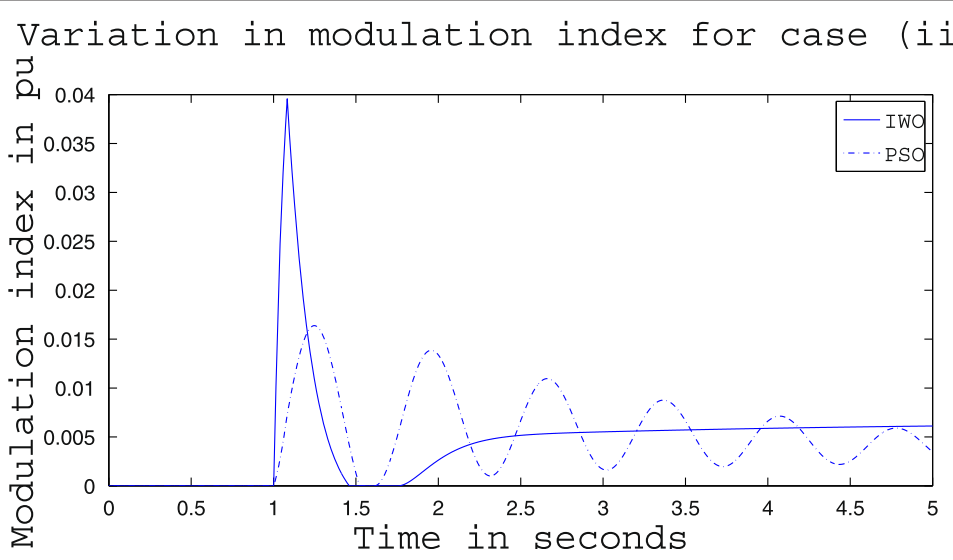

Figure 32 Variation of control signal $m_{b}$ for case (iii) under heavy load condition. 
Table 3 Optimized parameters of IWO and PSO for different case studies

\begin{tabular}{|c|c|c|c|c|}
\hline Optimizer & Case & Loading & $K_{p}$ & $\mathrm{~K}_{\mathrm{i}}$ \\
\hline & 1 & Light & 1 & 28 \\
\hline & & Nominal & 1 & 28 \\
\hline & & Heavy & 1 & 12.5119 \\
\hline & $\|$ & Light & 1 & 17.9417 \\
\hline \multirow[t]{9}{*}{ PSO } & & Nominal & 1 & 14.5325 \\
\hline & & Heavy & 1 & 25.4302 \\
\hline & III & Light & 1 & 6.2319 \\
\hline & & Nominal & 1 & 6.6266 \\
\hline & & Heavy & 1 & 21.9208 \\
\hline & 1 & Light & 17.760 & 28 \\
\hline & & Nominal & 20.454 & 27.3489 \\
\hline & & Heavy & 9.8019 & 21.9525 \\
\hline & ॥ & Light & 4.3441 & 11.4455 \\
\hline \multirow[t]{5}{*}{ IWO } & & Nominal & 4.3441 & 11.4455 \\
\hline & & Heavy & 11.4738 & 15 \\
\hline & III & Light & 4.3441 & 11.4455 \\
\hline & & Nominal & 4.3441 & 11.4455 \\
\hline & & Heavy & 15 & 0.8943 \\
\hline
\end{tabular}

\section{Appendix}

Synchronous Generator: (2100 MVA, $13.8 \mathrm{kV})$.

$\mathrm{f}_{\mathrm{b}}=60 \mathrm{~Hz}, \omega_{0}=377 \mathrm{rad} / \mathrm{sec}, \mathrm{D}=0, \mathrm{M}=8.0 \mathrm{MJ} / \mathrm{MVA}$,

$x_{d}=1.0$ p.u., $x_{d}^{\prime}=0.3$ p.u., $x_{q}=0.6$ p.u., $T_{d 0}^{\prime}=5.044$ sec.

Exciter: $\mathrm{K}_{\mathrm{A}}=10.0, \mathrm{~T}_{\mathrm{A}}=0.01 \mathrm{sec}$.

SSSC: $\mathrm{S}_{\text {nom }}=100 \mathrm{MVA}, \mathrm{V}_{\text {noms }}=500 \mathrm{kV}$ (AC side),

$\mathrm{V}_{\text {nomp }}=5 \mathrm{kV}$ (DC side), $\mathrm{V}_{\text {dcrated }}=2 * \mathrm{~V}_{\text {nomp }}, \mathrm{C}_{\mathrm{dc}}=2.0 \mathrm{p}$.

u., $\mathrm{V}_{\mathrm{dc} 0}=10.0$ p.u., $\mathrm{m}_{\mathrm{b} 0}=0, \delta_{b}=-30.88^{\circ}, \mathrm{m}_{\mathrm{b} \max }=1.0$,

$\mathrm{m}_{\text {bmin }}=0$.

Transformer: (2100 MVA, 13.8/500 kV).

$\mathrm{X}_{\mathrm{t}}=0.1$ p.u.,

Transmission Line: $\mathrm{X}_{\mathrm{L} 1}=\mathrm{X}_{\mathrm{L} 2}=0.3$ p.u.

Infinite Bus: $V_{b}=1.0$ p.u.

PI Controller gain Limits: $K_{\text {pmin }}=K_{\text {imin }}=1$,

$\mathrm{K}_{\mathrm{pmax}}=\mathrm{K}_{\mathrm{imax}}=28$.

\section{Competing interest}

The authors declare that they have no competing interest.

\section{Authors' contributions}

AA took part in literature survey, theoretical modeling, software simulation, result processing and draft preparation. RAA took part in literature survey, software simulation and result processing. RA took part in result processing and simulation. All authors read and approved the final manuscript.

\section{Author details}

'EEE Department, Islamic University of Technology, Board Bazar, Bangladesh. ${ }^{2}$ ETE Department, International Islamic University, Chittagong, Bangladesh. ${ }^{3}$ EEE Department, Bangladesh University of Business and Technology, Dhaka, Bangladesh.

Received: 29 November 2013 Accepted: 14 July 2014

Published: 30 July 2014

\section{References}

Acha E, Esquivel CRF, Perez HA, Camacho CA (2004) FACTS: Modeling and Simulation in Power Networks. John Wiley and Sons Ltd, The Atrium, Southern Gate, Chichester, West Sussex PO19 8SQ, England

Ajami A, Armaghan M (2010) Application of multi-objective PSO algorithm for power system stability enhancement by means of SSSC. Int J Comput Electrical Eng 2(5):838-845

Anderson PM, Fouad AA (1977) Power System Control and Stability. The IOWA State University Press. AMES, IOWA, USA

Ardakani MS, Rshanaei M, Kian AR, Lucas C (2008) A study of Electricity Market Dynamics using Invasive Weed Colonization Optimization. Paper Presented at IEEE Symposium on Computational Intelligence and Games. CIG '08, Perth, Australia, 15-18, Dec., 2008

David FM, Venkataramanan G (2007) Modeling and Control of the Static Synchronous Series Compensator under Different Operating Modes. Paper presented at Power Electronics Specialists Conference. PESC 2007, IEEE, Orlando, FL, 17-21 June, 2007

Ghaisari J, Bakhshai A (2005) Power Oscillation Damping Improvement by Means of a Feedback Linearized Solid State Series Controller, Proceedings of the 2005 IEEE Conference on Control Applications. IEEE, Ontario, Toronto, Canada, pp 629-634, August 28-31, 2005

Gu L, Zhou X, Liu M, Shi H (2010) Nonlinear adaptive controller design of SSSC for damping inter-area oscillation. WSEAS Trans Circuits Syst 9(4):228-237

Gyugi L, Schauder CD, Sen KK (1997) Static synchronous series compensator: a solid-state approach to the series compensation of transmission lines. IEEE Trans Pow Deliv 12(1):406-417

Hingorani NG, Gyugi L (2000) Understanding FACTS: Concepts and Technology of Flexible AC Transmission Systems. IEEE Press, New York

Kennedy J, Eberhart RC (1995) Particle swarm optimization, Proceedings of IEEE International Conference on Neural Networks, vol. 4th edn. IEEE, Perth, Australia, pp 1942-1948, Nov. 27 - Dec 01, 1995

Kundur P (1994) Power System Stability and Control. McGraw-Hill Inc, New York

Mallahzadeh AR, Eshaghi S, Alipour A (2009) Design of an E shaped MIMO antenna using IWO algorithm for wireless application at 5.8 Ghz. Prog Electromagn Res 90:187-203

Mehrabian AR, Lucas C (2006) A novel Numerical optimization algorithm inspired from weed colonization. J Ecol Inform 1(4):355-366

Mehrabian AR, Yousefi-Koma A (2007) Optimal positioning of piezoelectric actuators on a smart fin using bio-inspired algorithms. Aerosp Sci Technol 11:174-182

Murali D, Rajaram M (2010) Intelligent control schemes for SSSC based damping controllers in multi-machine power systems. Int J Eng Sci Technol 2(8):3788-3796

Padiyar KR (2007) FACTS Controllers in Power Transmission and Distribution. BS Publications, Hyderabad

Pandey RK, Singh NK (2008) Optimal Power Oscillation Damping with SSSC. Paper presented at TENCON 2008 - IEEE Region 10 Conference, Hyderabad, 19-21 Nov., 2008

Rad HS, Lucas C (2007) A Recommender System based on Invasive Weed Optimization Algorithm. Paper presented at IEEE Congress on Evolutionary Computation. CEC 2007, Singapore, 25-28 Sep. 2007

Swain SC, Balirsingh AK, Mahapatra S, Panda S (2011) Design of static synchronous series compensator based damping controller employing real coded genetic algorithm, international journal of electrical. Electron Sci Eng 5(3):31-39

Swain SC, Mahapatra S, Panda S, Panda S (2012) Design of DE optimized SSSC-based FACTS controller. Int J Electron Electrical Eng 2(4):12-27

Swain SC, Mahapatra S, Panda S (2013) Design of DE optimized SSSC-based FACTS controller. Int J Electron Commun Eng Technol 2(4):12-27

Therattil JP, Panda PC (2011) Improving Dynamic Stability of a Power System using Adaptive Static Synchronous Series Compensator. Paper Presented at TENCON 2011. IEEE Region 10 Conference, Bali, Indonesia, 21-24 Nov. 2011

Therond P (1999) Modeling of power electronics equipment (FACTS) in load flow and stability programs: A Representation Guide for Power System Planning and Analysis (1999), Aug 1999, CIGRE Study Committee 38. Task Force 38.01.08. CIGRE, Paris

Zhang XP, Rehtanz C, Pal B (2006) Flexible AC Transmission Systems: Modeling and Control. Springer, Berlin-Heidelberg

Zhang X, Cui G, Niu Y, Xu J (2009) Application of a Novel IWO to the Design of Encoding Sequence for DNA Computing. Paper Presented at International Conference on Bio-Inspired Computing-Theories and Applications. BIC-TA2007, Zhengzhou, China, June 2009

doi:10.1186/2193-1801-3-394

Cite this article as: Ahmed et al:: Design of static synchronous series compensator based damping controller employing invasive weed optimization algorithm. SpringerPlus 2014 3:394. 